\title{
Lysophosphatidyl choline in the aqueous humour during ocular inflammation*
}

\author{
A. G. SECCHI, I. FREGONA, AND F. D'ERMO \\ From the Research Unit for Ocular Allergy and Immunology, Institute of Ophthalmology, University of \\ Padova
}

SUMmaRY Phospholipase A and lysophosphatidyl choline (LPC) have been shown to induce significant changes in the lens permeability in vitro to cations and soluble proteins. During uveal inflammation, in various experimental models and in man as well, the levels of LPC in the aqueous humour have been shown to reach values which are harmful to the lens in vitro. In addition, a phospholipase is thought to be activated during the antigen + antibody + complement sequence. The possible significance of these findings is discussed in relation to the pathogenesis of complicated cataracts in uveitis and the possible role of the lens as a source of autoantigens in recurrent uveitis.

Phospholipids are an essential constituent of every cell membrane. According to a recent theory the 'framework' of cell membranes is formed by a bilayer of lipids whose hydrophilic 'heads' form the internal and external surfaces, while hydrophobic 'tails' join in the centre of the membrane. In intracellular membranes lipids consist mainly of phospholipids, while cytoplasmic membranes contain phospholipids, glycolipids, and neutral lipids (Capaldi, 1974).

Phosphatidyl choline (lecithin) is essential among membrane phospholipids and is hydrolysed by ubiquitous enzymes, phospholipases, to lysophosphatidyl choline (lysolecithin or LPC). Changes in LPC levels in a given tissue and/or fluid may thus be considered as an index of changed phospholipase activity. In the anterior chamber of the eye, however, an increase in the LPC level may be due also to the breakdown of a blood-aqueous barrier (Cotlier et al., 1976) specific for phospholipids.

Normal rabbit aqueous contains $2 \cdot 3 \quad( \pm 1 \cdot 5)$ $\mu \mathrm{gLPC} / \mathrm{ml}$ according to Varma and Reddy (1972), $4.3 \mu \mathrm{g}$ according to Cotlier (1976), $1.46( \pm 0.78) \mu \mathrm{g}$ in our experiments.

Local increases of phospholipase A and LPC (the former through a likely direct action on membrane phospholipids and the latter acting on the same substrate as a 'detergent') may induce changes in

*Part of this article was presented at the Third International Congress for Eye Research, Osaka, Japan, 21-25 May 1978

Correspondence to Professor A. G. Secchi, Istituto di Clinica Oculistica, 35100 Padova, Italy the normal lens permeability. Cotlier et al. (1975) have shown in vitro that $7.5 \mu \mathrm{gLPC} / \mathrm{ml}$ were enough to cause a significant gain of $\mathrm{Na}^{+}$and water to a lens in culture. We have shown that $10 \mu \mathrm{gLPC} / \mathrm{ml}$ induce a more important derangement in the lens permeability, allowing soluble lens proteins to leak out in the incubation medium (Secchi et al., 1976b; D'Ermo and Secchi, 1977). Similar results have been obtained in the presence of $0.33 \mu \mathrm{g} / \mathrm{ml}$ of phospholipase A. The leakage of cytoplasmic constituents under these situations is probably due to membrane ruptures following cellular swelling.

Any situation in which phospholipase $\mathbf{A}$ and/or LPC levels in the aqueous reach or exceed the threshold shown harmful to the lens is therefore a potential cause of cataract. In addition, the leakage of soluble lens protein, immunogenic as 'sequestered antigens', may lead to intraocular inflammation, possibly recurrent, by an autoimmune mechanism.

We thought it interesting to study LPC levels in the aqueous during experimental allergic and clinical uveitis. An increase beyond the levels known to be harmful might be relevant to the pathogenesis of complicated cataracts in uveitis and to the possible role of the lens as a source of autoantigen in the self-perpetuation of recurrent anterior non-granulomatous uveitis.

\section{Materials and methods}

Experimental allergic uveitis was induced by Eifrig and Prendergast's technique, modified by D'Ermo et al. (1975). Intravenous injections of an antigen 
into a rabbit whose anterior chamber was grafted with a piece of autologous lymph node 'activated' against the same antigen were followed by anterior uveal inflammations. The lipids were extracted according to the technique described by Bligh and Dyer (Sheltawy and Dawson, 1969). The residues, obtained by removing the solvent under nitrogen, were dissolved in a chloroform-methanol mixture $(1: 1 \mathrm{v} / \mathrm{v})$ and the lipids separated by thin-layer chromatography with the use of a chloroformmethanol-acetic-acid-water solution in the ratio $25: 15: 4: 2$.

Phospholipids spots were visualised on precoated silica gel plates (Precoated TLC Plates Silica Gel 60 F-254, Merck, Darmstadt, BRD) by exposure to iodine vapour and identified by standards run simultaneously. The gel from the areas containing the LPC was scraped off the plate and transferred to suitable tubes. Gel from adjacent areas of approximately the same size but containing no lipids was also scraped off and used as blank in the assay. Phospholipid phosphorus was estimated at ultramicrolevel as described by Bartlett (1959).

\section{Results and discussion}

The results of our experiments in vitro, which confirm and extend Cotlier's investigations, showed that 7.5 to $10 \mu \mathrm{gLPC} / \mathrm{ml}$ represents the minimum level clearly harmful to the lens (Secchi et al., 1976b). LPC at this level is responsible for a derangement of the normal lens permeability to cations and, later, to its own soluble proteins.

Samples of aqueous humour drawn in the course of experimental allergic uveitis showed levels of LPC much higher than in normal aqueous, very close to those shown to be harmful in vitro (Table 1).

Aqueous taps performed in patients suffering from anterior non-granulomatous uveitis showed similar results: in these cases LPC levels were also significantly increased, with a clear correlation between rate of increase and severity of inflammation.

Table 1 Levels of LPC in samples of aqueous humour

\begin{tabular}{ll}
\hline In normal aqueous (rabbit) & $1.46 \pm 0.78 \mu \mathrm{g} / \mathrm{ml}$ \\
Harmful in vitro to normal rabbit lens: & $7.5 \mu \mathrm{g} / \mathrm{ml} *$ \\
(a) gain in $\mathrm{Na}^{+}$and water & $10.0 \mu \mathrm{g} / \mathrm{ml} \dagger$ \\
(b) Leakage of soluble proteins & $9.35 \pm 2.7 \mu \mathrm{g} / \mathrm{ml}$ \\
In uveitic aqueous: & \\
(a) Rabbit & $9.66 \pm 1.7 \mu \mathrm{g} / \mathrm{ml}$ \\
(b) Man & $4.13 \mu \mathrm{g} / \mathrm{ml}$ \\
(1) Intense uveitis & \\
(2) Mild uveitis &
\end{tabular}

* From Cotlier et al. (1975). † From Secchi et al. (1976b)
The increased level of LPC in aqueous humour during inflammation may be due to a breakdown of the blood-aqueous barrier for phospholipids (Cotlier et al., 1976). We would point out, however, that an enhanced activity of phospholipase A may be responsible for an increase of lysophosphatidyl choline from cell membrane phosphatidyl choline. Phospholipase A activity, in fact, is enhanced during inflammation (from lysosomes and mast cells) and is thought to increase also during the final steps of the complement sequence.

The same phospholipase may also be responsible for a release of arachidonic acid from membrane phospholipids and, through a cyclic peroxide, for

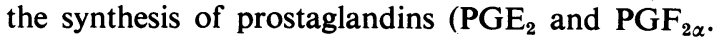
The level of prostaglandins in fact has been shown to increase in the aqueous humour during experimental or clinical uveitis. The effect of prostaglandins on the lens permeability has been investigated (Paterson and Eck, 1973), but the experimental results have shown that a derangement in the normal lens permeability may take place in vitro only when prostaglandins are present in the reaction medium at far higher concentrations than those found in the aqueous humour during inflammation.

Whether the rise of LPC in the aqueous is due to a breakdown of the blood-aqueous barrier and/or to an increase of phospholipase A activation, the fact remains that aqueous humour during inflammation, either experimental or clinical, contains 'factors' which are potentially cataractogenic. Moreover, the same factors may induce a leakage of soluble proteins from the lens in the surrounding media. These proteins have been shown to be immunogenic (Lanzieri and Secchi, 1965; Rahi et al., 1977) as 'sequestered antigens' and, thus, potential cause of inflammation when in contact with immunocompetent tissue.

The finding of antilens antibodies in the aqueous humour during uveitis is well established (Witmer, 1964; Luntz, 1968; Secchi et al., 1976a), and the development of a cell mediated immunity to the lens in the course of anterior uveitis has been reported by Henley et al. (1974). It is conceivable that both humoural and cellular immunity to the lens is the result of a leakage of immunogenic material from the lens itself.

Soluble lens proteins in the aqueous during inflammation have seldom been looked for, though Sandberg et al. (1974) showed a significant presence of $\alpha$-cristallin in human aqueous from eyes with Fuchs syndrome.

The rise of LPC in the aqueous humour during inflammation may therefore be relevant not only in the development of complicated cataracts in uveitis 
but also in the pathogenesis of recurrent anterior non-granulomatous uveitis, which to some extent would be phakogenic.

\section{References}

Bartlett, G. B. (1959). Phosphorus assay in column chromatography. Journal of Biological Chemistry, 234, 466-468.

Capaldi, R. A. (1974). Modello dinamico della membrana cellulare. Le Scienze, 12, 17-34.

Cotlier, E., Baskin, M., and Kresca, L. (1975). Effects of lysophosphatidyl choline and phospolipase $A$ on the lens. Investigative Ophthalmology, 14, 697-701.

Cotlier, E., Baskin, M., Kim, J. O., and Lueck, K. (1976). Lysophosphatidyl choline and cataracts in uveitis. Archives of Ophthalmology, 94, 1156-1162.

D'Ermo, F., Secchi, A. G., Mancini, B., and Fregona, I. (1975). Alterazioni della permeabilità del cristallino al ${ }^{86} \mathrm{Rb}$ in corso di uveite sperimentale allergica. Atti del LVI Congresso della Società Italiana d'Oftalmologia, pp. 218-221. Arte della Stampa: Rome.

D'Ermo, F., and Secchi, A. G. (1977). Phospholipase A und Lysophosphatidyl-cholin in dem Pathogenese von 'Permeabilitätskatarakt'. Klinische Monatsblätter für Augenheilkunde, 170, 433-440.

Henley, W. L., Okas, S., and Leopold, I. H. (1974). Human cellular immunity to lens; leukocyte migration inhibition by lens protein. Archives of Internal Medicine, 134, 684688.

Lanzieri, M., and Secchi, A. G. (1965). Immunization of rabbits with autologous lens homogenates. Archives of Ophthalmology, 74, 528-531.

Luntz H. (1968). Anti-uveal and anti-lens antibodies in uveitis and their significance. Experimental Eye Research, 7, 561-569.

Paterson, C. A., and Eck, A. (1973). Influence of prostaglandins on cation movement in the lens. Experimental Eye Research, 15, 767-778.

Rahi, A. H. S., Misra, R. N., and Morgan, G. (1977). Immunopathology of the lens. III. Humoral and cellular immune responses to autologous lens antigens and their roles in ocular inflammation. British Journal of Ophthalmology, 61, 371-379.

Sandberg, H. O., Følling, I., and Closs, O. (1974). Quantitation of alpha crystallin in human aqueous humor by radioimmunoassay. Acta Ophthalmologica, 52, 161-171.

Secchi, A. G., Segato, T., Mancini, B. (1976a). Release of protein and cations from the lens in presence of different antigen-antibody interaction. Modern Problems in Ophthalmology, 14, 80-94.

Secchi, A. G., Mancini, B., and Fregona, I. (1976b). Azione della fosfolipasi A e della lisofosfatidilcolina sulle membrane cellulari del cristallino. Atti del LVII Congresso della Società Italiana d'Oftalmologia, pp. 312-315. Arte della Stampa: Rome.

Sheltawy, W., and Dawson, R. M. C. (1969). Separation and estimation of phospholipids. In Chromatographic and Electrophoretic Techniques, Vol. I, 3rd edn., pp. 450-493. Edited by I. Smith. Heinemann Medical Books: Bath.

Varma, S. D., and Reddy, V. N. (1972). Phospholipid composition of aqueous humor, plasma and lens in normal and alloxan diabetic rabbits. Experimental Eye Research, 13, 120-125,

Witmer, R. (1964). Zur Frage der Auto-Immunerkrankung des Auges: Die phako-antigene Uveitis. International Archives of Allergy and Applied Immunology, 24, Supplement, 58-64. 